\title{
HIV and hepatitis C virus test uptake at methadone clinics in Southern China: opportunities for expanding detection of bloodborne infections
}

\author{
Ying-Hua Xia ${ }^{1,2}$, Wen Chen ${ }^{1,2}$, Joseph D Tucker ${ }^{2,3}$, Charles Wang ${ }^{3,4}$ and Li Ling ${ }^{1,2^{*}}$
}

\begin{abstract}
Background: HIV and hepatitis C ( $\mathrm{HCV}$ co-infection is highly common among Chinese injection drug users but it is difficult to reach IDUs at traditional VCT (Voluntary HIV counseling treatment) clinics. A new national model integrating HIV/HCV testing with methadone maintenance treatment was started in 2006. The purpose of this study was to investigate HIV and HCV test uptake and associated factors at methadone clinics in Guangdong Province, China.

Methods: A cross-sectional design using routine surveillance data and laboratory testing confirmation was applied to determine rates of HIV and HCV test uptake. Multi-level modeling was used to examine individual-level and clinic-level correlates of increased test uptake.

Results: 45 out of 49 methadone clinics in Guangdong Province agreed to participate in the study. Among all 13,270 individuals, 10,046 (75.7\%) had HIV test uptake and 10,404 (78.4\%) had HCV uptake. At the individual level, methadone clients 30 years or older were more likely to have HIV and HCV test uptake ( $<<0.001$ for both). At the clinic level, methadone clinics with greater health care personnel were more likely to have HIV ( $p=0.01)$ and HCV $(p=0.044)$ test uptake. HIV test uptake significantly correlated with HCV test uptake (correlation coefficient=0.64).

Conclusion: Methadone clinics provide an opportunity for routine integrated HIV and HCV screening among drug users in China. Increased test uptake in young drug users and increased health care personnel at clinics may further improve screening.
\end{abstract}

Keywords: Bloodborne infections, Testing uptake, Methadone maintenance treatment clinic

\section{Background}

Early HIV testing and treatment are critical to the success of comprehensive control programs, especially among most-at-risk populations [1,2]. Although HIV testing is offered in a variety of health care settings across the world, poor test uptake among drug users continues to be a common problem worldwide [3,4]. Currently less than half of HIV-infected individuals in China know their serostatus among the estimated 780,000 HIV-infected individuals [5]. Modeling research has suggested that increasing HIV testing fourfold in

\footnotetext{
* Correspondence: lingli@mail.sysu.edu.cn

${ }^{1}$ Faculty of Medical Statistics and Epidemiology, School of Public Health, Sun Yat-sen University, No. 74, Zhongshan Road II, Yuexiu District, Guangzhou 510080, P.R. China

${ }^{2}$ Sun Yat-sen Center for Migrant Health Policy, Sun Yat-sen University, No. 74 Zhongshan Road II, Yuexiu District, Guangzhou 510080, P.R. China

Full list of author information is available at the end of the article
}

China could avert over 42,000 HIV infection and 11,000 deaths [6]. Scaling up HIV testing has been challenging in China. Traditional voluntary HIV counseling treatment (VCT) testing has failed to reach many drug users in China. Less than 20\% of drug users in China received HIV testing at VCT sites $[7,8]$.

HIV and hepatitis C (HCV) co-infection is common among Chinese injection drug users (IDUs) [9]. In one study from southern China, $17.6 \%$ of IDUs had HCV infection and in $95.1 \%$ of $\mathrm{HCV}$-infected individuals also had HIV infection [10]. Since HIV/HCV co-infection increases mortality, cirrhosis, and hepatocellular carcinoma, scaling up integrated HIV and HCV testing is an important public health priority [11].

To address these challenges, in 2006 China started a model of HIV/HCV screening among drug users at methadone maintenance treatment clinics (methadone

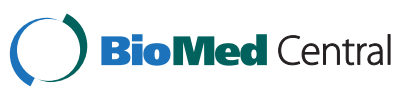


clinics) $[12,13]$. Free voluntary routine screening for HIV and $\mathrm{HCV}$ infection were integrated into methadone clinics and provided to all clients, although individuals could still decline testing. Currently 700 methadone clinics across China distribute methadone to 300,000 drug users and coverage continues to expand [14,15].

However, the extent to which this model successfully implements HIV and HCV testing in China is currently unknown. The purpose of this study was to examine $\mathrm{HIV}$ and $\mathrm{HCV}$ test uptake at methadone clinics in Guangdong Province, China and to identify individual and clinic level factors associated with increased uptake.

\section{Methods}

\section{Study site}

Guangdong Province is located in southern China and has the largest migrant population of any province [16]. The province has a system of 49 methadone clinics. Methadone clients are self-referred or assigned treatment as part of a post-incarceration rehabilitation plan [13]. The system is administered by the National Centre for AIDS/STD Control and Prevention within the Chinese Centers for Disease Control and Prevention (Chinese CDC). The system has associated clinics that distribute methadone to recovering drug users. Guangdong's 49 methadone clinics are distributed in 18 of the 23 cities of the province.

\section{Administrative management system}

A national web-based national HIV/AIDS information system was established by the Chinese CDC and includes methadone maintenance treatment as one of its eight core subsystems [17].

The methadone clinic administrative database has detailed records of all individuals, including sociodemographic characteristics, drug use behaviors, and HIV and HCV test uptake. Test uptake was defined as laboratory confirmed completion of an HIV Western Blot or HCV ELISA test. All surveys were completed by local methadone clinic staff and entered into the national web-based administrative management system. Survey items were developed by the National Working Group for Community-based Maintenance Treatment for Opiate Users [13].

\section{Data source}

We conducted a performance evaluation of the methadone maintenance program in Guangdong Province. Data for all 49 methadone clinics opened before October 31, 2008 were collected during November and December 2008. Methadone clinic staff downloaded data and deleted all identifying information.

The director of each methadone clinic completed a detailed questionnaire about their clinic including economic region, administrative clinic level, affiliated institution, clinic healthcare personnel (the total number of nurses and physicians employed), number of patients, integration of clinic with voluntary HIV counseling services, clinic finances (for profit or not), and average distance from client residence to clinic (within five kilometers or further).

\section{Data analysis}

A total of 49 clinics were examined. Four clinics open less than one month prior to the study were not included in the analysis. $172(1.3 \%)$ individuals were excluded from the analysis because they had three or more individual-level variables missing in their data set. Another 296 (2.2\%) individuals were excluded because they initiated methadone maintenance treatment in another province before transferring their care to Guangdong.

The main study outcomes were HIV test uptake and $\mathrm{HCV}$ test uptake. Group comparisons for categorical data were examined with Chi-square tests at the individual level. HIV and HCV test uptake were examined using nonparametric Kruskal-Wallis tests at the clinic level. The correlation between HIV test uptake and $\mathrm{HCV}$ test uptake was examined using a Pearson correlation coefficient.

Given the hierarchical nature of the data, there was potential clustering in outcomes and interactions between individual and clinic level factors of HIV and $\mathrm{HCV}$ test outcomes. Multilevel analysis with random intercepts was used to assess the effect of factors at the individual and clinical level on HIV and HCV test uptake. To examine clustering at the clinic level, a random intercept two-level null model with no explanatory variables was first tested. Results were consistent with clustering at the clinic level, supporting the use of a multilevel model.

The multilevel analysis used a two-level binomial logit model that incorporated six individual level (level 1) variables and eight clinic level variables (level 2). Individual level socio-demographic characteristics included the following: sex, age ( $<30$ years old, 30-39 years old, 4049 years old, $>50$ years old), marital status (married, unmarried), education completed (none/primary school, middle school, high school and above), and employment status (employed, unemployed). Behavioral data in the system included major drug type, injecting behaviors (injecting, non-injecting), drug use method during the past half year (injecting, smoking/snorting, mixing injecting and smoking/snorting), needle sharing experience (sharing, non-sharing) and detoxification experience (ever had detoxification, never). Only drug injecting experience was included in the analysis. Major drug type and detoxification experience were not included because more than 90\% of individuals were heroin addicts and almost all of them had detoxification experience. Drug use during the 
past half year and needle sharing experience were excluded since they were highly correlated with injecting drug experience. All clinic level variables mentioned above were included. Clinic healthcare personnel (physicians and nurses) and total number of individuals at each clinic were fitted as continuous variables. The form of the binomial logit 2-level model and interpretation are described elsewhere [18]. Stepwise selection was used to choose the variables for the final model, first using individual level variables and then using clinic level variables. The final model was designed by first including all variables in the model that were significant and then examining the best fit based on -2log-likelihood values [19]. Models were created using discrete variables as dummy or grouped continuous variables and -2log-likelihood values were compared.

Analysis used SAS 9.1 (SAS Institute Inc, Cary, NC, USA) except for the multilevel analysis which used MLwiN 2.02 (http://www.cmm.bristol.ac.uk/MLwiN/). Reported p-values were two-sided and a p-value below 0.05 was judged significant.

\section{Ethics statement}

This study was approved by the Guangdong Provincial Health Bureau and the Ethics Review Committee at Sun Yat-sen University. Written informed consent was provided by clinic directors and all patients. The patient consent included permission to upload information into the national web-based administrative database.

\section{Results}

\section{Socio-demographic characteristics of participants} and characteristics of clinics

A total of 13,270 individuals were included in this analysis. Most individuals were male (93.9\%) and heroin users (99.6\%). 82.6\% were between 20 years old and 40 years old. Most individuals had completed nine years or less of school and were unemployed at the time of the survey (Table 1).Twenty-five out of the 45 clinics were located in the prosperous Pearl River Delta region of the province. $82.2 \%$ of clinics were at the city level. The median total number of methadone clients seen in

Table 1 Individual-level characteristics associated with HIV and HCV test uptake at methadone clinics $(\mathrm{N}=13270)$

\begin{tabular}{|c|c|c|c|c|c|}
\hline \multirow[t]{2}{*}{ Variables } & \multirow[t]{2}{*}{ No. of patients (\%) } & \multicolumn{2}{|c|}{ HIV uptake } & \multicolumn{2}{|c|}{ HCV uptake } \\
\hline & & No. (\%) & $\mathbf{p}$ & No. (\%) & $p$ \\
\hline Overall & 13270(100) & $10046(75.7)$ & & 10404(78.4) & \\
\hline \multicolumn{6}{|l|}{ Sex } \\
\hline Male & 12463(93.9) & $9400(75.4)$ & 0.003 & $9753(78.3)$ & 0.106 \\
\hline Female & $807(6.1)$ & $646(80.1)$ & & $651(80.7)$ & \\
\hline \multicolumn{6}{|l|}{ Age } \\
\hline$<20$ years old & $36(0.3)$ & $25(69.4)$ & $<0.001$ & $25(69.4)$ & $<0.001$ \\
\hline 20-29 years old & $3242(24.4)$ & $2346(72.4)$ & & $2411(74.4)$ & \\
\hline 30-39 years old & $7725(58.2)$ & $5907(76.5)$ & & 6148(79.6) & \\
\hline 40-49 years old & $2080(15.7)$ & $1621(77.9)$ & & 1664(80.0) & \\
\hline 50-59 years old & $177(1.3)$ & $140(79.1)$ & & $149(84.2)$ & \\
\hline$>59$ years old & $10(0.1)$ & $7(70.0)$ & & $7(70.0)$ & \\
\hline \multicolumn{6}{|l|}{ Marital status } \\
\hline Married & 6446(48.6) & $4911(76.2)$ & 0.208 & $5079(78.8)$ & 0.288 \\
\hline Unmarried & $6824(51.4)$ & $5135(75.3)$ & & $5325(78.0)$ & \\
\hline \multicolumn{6}{|l|}{ Education } \\
\hline None/primary school & $2760(20.8)$ & 1695(77.6) & 0.049 & 2158(78.2) & 0.661 \\
\hline Middle school & $8325(62.7)$ & $6292(75.6)$ & & $6517(78.3)$ & \\
\hline High school and above & 2185(16.5) & 2059(74.6) & & $1729(79.1)$ & \\
\hline \multicolumn{6}{|l|}{ Employment status } \\
\hline Employed & 4926(37.1) & $3752(76.2)$ & 0.340 & $3650(74.1)$ & $<0.001$ \\
\hline Unemployed & $8344(62.9)$ & $6294(75.4)$ & & $6754(80.9)$ & \\
\hline \multicolumn{6}{|l|}{ Ever injected drugs } \\
\hline Yes & $11011(83.0)$ & 8348(75.8) & 0.512 & $8663(78.7)$ & 0.091 \\
\hline No & $2259(17.0)$ & 1698(75.2) & & $1741(77.1)$ & \\
\hline
\end{tabular}

Note: uptake is defined as completion of HIV or HCV test at an associated laboratory. 
each clinic was 280 (range 21-1029). The median number of healthcare personnel at each clinic was 5 (range 2-10) (Table 2).

\section{Individual-level characteristics associated with HIV and HCV test uptake}

Among all 13,270 individuals, 10,046 (75.7\%) had HIV test uptake and 10,404 (78.4\%) had HCV uptake. Among IDUs and non-IDUs, the HIV prevalence was $7.0 \%$ and $0.8 \%$, respectively. Among IDUs and non-IDUs, the HCV prevalence was $75.5 \%$ and $32.6 \%$, respectively. Several individual factors were significantly associated with HIV test uptake and HCV test uptake using univariate analysis (Table 1). Women had a HIV uptake rate of 80.1\% compared to men who had an HIV uptake rate of
75.4\% ( $\mathrm{P}=0.003)$. HIV uptake and HCV uptake were increased among older individuals $(\mathrm{P}<0.001)$. Individuals younger than twenty years old had the lowest HIV and HCV uptake (both were 69.4\%) and individuals between 50 to 59 years old had the highest HIV and HCV uptake ( $79.1 \%$ and $84.2 \%$, respectively). Individuals who were unemployed had higher HCV uptake $(80.9 \%)$ than individuals who were employed $(74.1 \%)(\mathrm{P}<0.001)$.

\section{Clinic level characteristics associated with HIV and HCV test uptake}

At the clinic level, the median HIV test uptake among 45 clinics was $86.4 \%\left(\mathrm{P}_{25}-\mathrm{P}_{75}: 71.8 \%-98.6 \%\right)$ and the median HCV test uptake was $94.9 \%$ (83.1\%-97.8\%). No

Table 2 Clinic-level characteristics associated with HIV and HCV test uptake at methadone clinics ( $\mathrm{N}=45$ )

\begin{tabular}{|c|c|c|c|c|c|c|c|}
\hline \multirow[t]{2}{*}{ Variables } & \multirow[t]{2}{*}{ No. of clinics (\%) } & \multicolumn{3}{|c|}{ HIV test uptake (\%) } & \multicolumn{3}{|c|}{ HCV test uptake (\%) } \\
\hline & & Median & $P_{25}-P_{75}$ & $P$ & Median & $P_{25}-P_{75}$ & $P$ \\
\hline Overall & $45(100)$ & 86.4 & $71.8-98.6$ & & 94.9 & $83.1-97.8$ & \\
\hline \multicolumn{8}{|l|}{ Economic region } \\
\hline Pearl River Delta* & $25(55.6)$ & 87.1 & 79.5-98.7 & 0.209 & 94.9 & $85.0-97.9$ & 0.385 \\
\hline Non-Pearl River Delta & $20(44.4)$ & 84.8 & $57.9-97.0$ & & 90.4 & $71.0-97.5$ & \\
\hline \multicolumn{8}{|l|}{ Administrative clinic level } \\
\hline Town/village level & $8(17.8)$ & 83.1 & $79.2-97.1$ & & 96.8 & $57.3-97.8$ & \\
\hline City level & $37(82.2)$ & 86.8 & 63.9-98.7 & 0.894 & 92.4 & $83.1-97.8$ & 0.859 \\
\hline \multicolumn{8}{|l|}{ Affiliated institution ${ }^{* *}$} \\
\hline Center of Disease Control (CDC) & $13(28.9)$ & 86.8 & 72.9-97.7 & 0.679 & 96.1 & $84.5-96.9$ & 0.940 \\
\hline Non-CDC & $32(71.1)$ & 85.2 & $63.3-98.7$ & & 93.6 & $82.4-97.9$ & \\
\hline \multicolumn{8}{|l|}{ Clinic healthcare personnel } \\
\hline $2-4$ staff & 13(28.9) & 63.9 & $54.1-89.7$ & 0.079 & 83.1 & $71.0-95.0$ & 0.154 \\
\hline $5-7$ staff & $27(60.0)$ & 86.2 & 72.9-98.6 & & 96.4 & $84.7-98.3$ & \\
\hline 8-10 staff & $5(11.1)$ & 97.7 & 89.8-98.9 & & 96.6 & $90.9-99.6$ & \\
\hline \multicolumn{8}{|l|}{ Total number of patients } \\
\hline$<200$ patients & $17(37.8)$ & 89.7 & $72.9-97.7$ & 0.462 & 96.6 & $86.7-97.9$ & 0.345 \\
\hline 200-399 patients & $17(37.8)$ & 86.4 & $63.9-98.8$ & & 92.4 & $84.5-97.5$ & \\
\hline$>=400$ patients & $11(24.4)$ & 82.8 & 35.0-98.0 & & 84.7 & $31.8-98.3$ & \\
\hline \multicolumn{8}{|c|}{ Provided voluntary HIV counseling or not } \\
\hline Yes & $29(64.4)$ & 86.8 & 78.9-98.7 & 0.484 & 95.0 & $84.5-97.9$ & 0.652 \\
\hline No & $16(35.6)$ & 84.0 & $57.9-96.8$ & & 92.9 & $81.1-97.4$ & \\
\hline \multicolumn{8}{|c|}{ Average distance from clients' residence to clinic } \\
\hline$\leq 5 \mathrm{~km}$ & $20(44.4)$ & 86.8 & $62.7-99.0$ & 0.991 & 88.4 & $75.0-97.7$ & 0.615 \\
\hline$>5 \mathrm{~km}$ & $25(55.6)$ & 86.2 & 72.9-97.7 & & 96.1 & 83.3-97.8 & \\
\hline \multicolumn{8}{|l|}{ Clinic made profit or not } \\
\hline Yes & $19(42.2)$ & 86.2 & $63.4-98.8$ & 0.973 & 96.4 & $85.2-97.8$ & 0.491 \\
\hline No & $26(57.8)$ & 86.6 & $72.1-97.7$ & & 88.8 & 81.8-97.9 & \\
\hline
\end{tabular}

*Pearl River Delta: A dense network of economically developed cities in South China.

**Affiliated institution: A methadone clinic is not an independently operated institution. Clinics are affiliated to institutions such as a local Center of Disease Control, public comprehensive hospital or specialist hospital. The affiliated institution manages the clinic, becomes responsible for administrative issues, and provides human resources and equipment to the clinic. 
factors were significantly associated with clinic test uptake based on the univariate analysis (Table 2).

HIV test uptake - individual and clinic level associations The final two-level logit model showed age, sex, drug injecting experience and clinic healthcare personnel were associated with HIV test uptake. Younger individuals were less likely to have HIV test uptake than older individuals. Non-injecting drug users were more likely to have HIV test uptake than IDUs $(\mathrm{OR}=1.16,95 \%$ $\mathrm{CI}=1.01-1.33)$. Women had higher HIV uptake than men $(\mathrm{OR}=1.36,95 \%=1.08-1.70)$. Clinics with greater healthcare personnel had higher HIV uptake $(\mathrm{OR}=1.55$, 95\% CI=1.09-2.20) (Table 3).

HCV test uptake - individual and clinic level associations As shown in Table 4, the final model identifying correlates of HCV test uptake included age, employment status and clinic healthcare personnel. Similar to HIV test uptake data, older individuals were more likely to have $\mathrm{HCV}$ test uptake than younger individuals (the OR

\begin{tabular}{|c|c|c|}
\hline Parameters & Estimate(s.e.) & $\begin{array}{c}\text { Odds ratio } \\
\text { (95\% confidence } \\
\text { interval) }\end{array}$ \\
\hline
\end{tabular}

Null model

Random

Level 2

$\sigma_{\mu_{\mathbf{o}}}^{2}$ $4.227(0.947)$

$<0.001$

Model with explanatory

variables

Random

Level 2

$\sigma_{\mu_{0}}^{2}$

$3.720(0.854)$

Fixed

Age

$<30$ years old

30-39 years old

40-49 years old

$>50$ years old

Sex

Male

Female

$0.305(0.114) \quad 1.36(1.08,1.70)$

Ever injected drugs

Yes

No

$0.229(0.062)$

$0.490(0.087)$

$0.401(0.231)$

$1.26(1.11,1.42)$

$1.63(1.38,1.94)$

$1.49(0.95,2.35)$

$<0.001$

$<0.001$

0.082

0.007

Clinic healthcare personnel* $\quad 0.439(0.178) \quad 1.55(1.09,2.20) \quad 0.013$

*: Healthcare personnel are defined as the total number of physicians and nurses at the clinic.
Table 4 Factors associated with HCV test uptake using multilevel model

\begin{tabular}{|c|c|c|c|}
\hline Parameters & Estimate(s.e.) & $\begin{array}{c}\text { Odds ratio } \\
\text { (95\% confidence } \\
\text { interval) }\end{array}$ & $P$ \\
\hline \multicolumn{4}{|l|}{ Null model } \\
\hline \multicolumn{4}{|l|}{ Random } \\
\hline \multicolumn{4}{|l|}{ Level 2} \\
\hline$\sigma_{\mu_{0}}^{2}$ & $4.427(0.991)$ & & $<0.001$ \\
\hline \multicolumn{4}{|l|}{$\begin{array}{l}\text { Model with explanatory } \\
\text { variables }\end{array}$} \\
\hline \multicolumn{4}{|l|}{ Random } \\
\hline \multicolumn{4}{|l|}{ Level 2} \\
\hline$\sigma_{\mu_{0}}^{2}$ & $4.103(0.942)$ & & $<0.001$ \\
\hline \multicolumn{4}{|l|}{ Fixed } \\
\hline \multicolumn{4}{|l|}{ Age } \\
\hline$<30$ years old & - & 1 & \\
\hline 30-39 years old & $0.258(0.071)$ & $1.29(1.13,1.49)$ & $<0.001$ \\
\hline 40-49 years old & $0.433(0.100)$ & $1.54(1.27,1.88)$ & $<0.001$ \\
\hline$>50$ years old & $0.725(0.302)$ & $2.06(1.14,3.73)$ & 0.016 \\
\hline \multicolumn{4}{|l|}{ Employment status } \\
\hline Employed & - & 1 & 0.014 \\
\hline Unemployed & $0.161(0.066)$ & $1.17(1.03,1.34)$ & \\
\hline Clinic healthcare personnel* & $0.379(0.188)$ & $1.46(1.01,2.11)$ & 0.044 \\
\hline
\end{tabular}

of $30-39$ and $40-49$ versus under 30 years are 1.29 (95\% $\mathrm{CI}=1.13-1.49)$ and $1.54(95 \% \mathrm{CI}=1.27-1.88))$. More healthcare personnel at the methadone clinic were associated with higher $\mathrm{HCV}$ test uptake (OR=1.46, 95\% $\mathrm{CI}=1.01-2.11)$. Unemployed individuals were more likely to have $\mathrm{HCV}$ test uptake than employed individuals $(\mathrm{OR}=1.18,95 \% \mathrm{CI}=1.03-1.34)$.

\section{Correlation between HIV and HCV uptake}

There was a significant correlation between HIV test uptake and HCV test uptake. The correlation coefficient between HIV test uptake and HCV test uptake was 0.64 $(\mathrm{P}<0.001)$. Among the 11,254 individuals who received either test, 1208 (10.7\%) received only HIV testing or $\mathrm{HCV}$ testing, but not both. Women (OR 1.57(95\% $\mathrm{CI}=1.14-2.15)$ ), individuals 40 to 49 years old (OR 1.53 (95\% CI=1.20-1.94)), and non-IDUs (OR 1.42 (95\% $\mathrm{CI}=1.16-1.74)$ ) were more likely to have received both HIV and HCV testing (Table 5).

\section{Discussion}

This study reveals an opportunity to expand detection of bloodborne infections at methadone clinics in China. To our knowledge, this study is the first to examine integrated HIV and HCV test uptake in Chinese methadone 


\begin{tabular}{|c|c|c|c|c|}
\hline Parameters & $\begin{array}{l}\text { Rate of } \\
\text { testing } \\
(\%)\end{array}$ & $\begin{array}{l}\text { Estimate } \\
\text { (s.e.) }\end{array}$ & $\begin{array}{c}\text { Odds ratio (95\% } \\
\text { confidence } \\
\text { interval) }\end{array}$ & $\mathbf{P}$ \\
\hline \multicolumn{5}{|l|}{ Null model } \\
\hline \multicolumn{5}{|l|}{ Random } \\
\hline \multicolumn{5}{|l|}{ Level 2} \\
\hline$\sigma_{\mu_{0}}^{2}$ & & $\begin{array}{l}2.913 \\
(0.629)\end{array}$ & & $<0.001$ \\
\hline \multicolumn{5}{|l|}{$\begin{array}{l}\text { Model with } \\
\text { explanatory } \\
\text { variables }\end{array}$} \\
\hline \multicolumn{5}{|l|}{ Random } \\
\hline \multicolumn{5}{|l|}{ Level 2} \\
\hline$\sigma_{\mu_{0}}^{2}$ & & $\begin{array}{l}2.866 \\
(0.619)\end{array}$ & & $<0.001$ \\
\hline \multicolumn{5}{|l|}{ Fixed } \\
\hline \multicolumn{5}{|l|}{ Age } \\
\hline$<30$ years old & 10.7 & - & 1 & \\
\hline 30-39 years old & 10.9 & $\begin{array}{c}0.166 \\
(0.089)\end{array}$ & $1.18(0.99,1.41)$ & 0.0617 \\
\hline 40-49 years old & 10.0 & $\begin{array}{c}0.424 \\
(0.122)\end{array}$ & $1.53(1.20,1.94)$ & $<0.001$ \\
\hline$>50$ years old & 12.0 & $\begin{array}{c}0.027 \\
(0.283)\end{array}$ & $1.03(0.59,1.79)$ & 0.924 \\
\hline \multicolumn{5}{|l|}{ Sex } \\
\hline Male & 10.9 & - & 1 & \\
\hline Female & 8.2 & $\begin{array}{c}0.448 \\
(0.161)\end{array}$ & $1.57(1.14,2.15)$ & 0.005 \\
\hline \multicolumn{5}{|l|}{$\begin{array}{l}\text { Ever injected } \\
\text { drugs }\end{array}$} \\
\hline Yes & 11.0 & - & 1 & $<0.001$ \\
\hline No & 9.5 & $\begin{array}{c}0.349 \\
(0.104)\end{array}$ & $1.42(1.16,1.74)$ & \\
\hline
\end{tabular}

clinics. China's model of routine screening at methadone clinics expanded access to HIV and HCV test among drug users, but our study found more than $20 \%$ of individuals seen at methadone clinics were still not screened for HIV or HCV. Older clients and more healthcare personnel at clinics were both associated with a higher test uptake. Our large sample size and incorporation of clinic level factors expands on previous research in this field $[8,20,21]$.

We found a high rate of HIV and HCV test uptake at methadone clinics. HIV test uptake rates in our study were similar to HIV test uptake rates reported in VCT clinics (72.7\%) and STI clinics $(81.2 \%)$ [18,22]. In China, methadone clinics are well positioned to scale up testing because many new HIV and HCV infections are acquired through drug use [7]. We found an HCV prevalence (75.5\%) higher than reported in a national systemic review (66.97\%) [9].
Free HCV testing at methadone clinics eliminates a potential barrier to screening associated with clinic-based testing. One study showed IDUs preferred methadone clinics more than general medicine clinics or specialized clinics as locations for HIV and HCV testing [23]. Our research suggests that routine $\mathrm{HIV} / \mathrm{HCV}$ screening at methadone clinics can provide a successful model for scaling up HIV/HCV prevention and control programs.

We found younger individuals at methadone clinics had poor HIV and HCV test uptake. While other Chinese studies have not observed the same trend $[18,24]$, our findings are consistent with the literature outside of China. Suboptimal HIV test uptake among youth has also been noted in the United States, Thailand, and Canada [25-27]. Poor awareness of infection, fear of knowing the results, and fear of stigma may be exacerbated among drug using youth [28-30] and were correlated with not receiving HIV testing among young people [31-33]. Since youth drug abuse is becoming more common in China [12] and HIV and $\mathrm{HCV}$ infection among young drug users are increasing $[10,34]$, developing tailored counseling for young individuals at methadone clinics may improve HIV and HCV test uptake.

Our findings suggest that lack of healthcare personnel may constrain HIV and $\mathrm{HCV}$ testing at methadone clinics. After adjusting for individual and clinic level factors, clinics with a higher number of healthcare personnel (physicians and nurses) were more likely to have HIV and HCV test uptake. Fewer healthcare personnel contribute to relatively heavier workloads and may lead to inadequate counseling during routine testing [35]. National methadone clinic guidelines require each clinic have two attending physicians and two nurses with training in mental health, HIV counseling, and methadone maintenance [13]. Our research found only $23.3 \%$ and $34.9 \%$ of methadone clinics in Guangdong province met these physician and nurse staffing requirements, respectively [36]. Other research suggests limited staffing is a problem throughout China [35] and to a lesser extent, the U.S [37]. Often two or three part-time clinicians are managing care for more than 100 patients, including writing prescriptions, providing counseling and health education, tracking patients lost to follow-up, and preparing reports [38]. Limited staffing may contribute to low quality counseling service, a known barrier to HIV testing [15,24]. Increasing the number of methadone clinic nurses may help expand routine HIV and $\mathrm{HCV}$ testing.

This study has several limitations. First, our use of routine monitoring data did not identify reasons for non-uptake. Although several correlates were associated with non-uptake, the broader social context of this missed public health opportunity can only be inferred. Second, our data were obtained from a single province in South China. However, Guangdong Province is diverse and draws 
individuals from a broad number of provinces and regions throughout China. Third, some individuals have HIV/HCV testing in other rehabilitation settings before methadone treatment, leading to individuals declining repeat testing. Research examining methadone clients perspectives is necessary to comprehensively interpret our results. Fourth, the data was collected at the end of 2008, but national policies have not changed since then. Finally, we have no data on the extent of test counseling at each clinic. Measuring this process outcome is important for ensuring that testing can be expanded.

\section{Conclusion}

Our findings emphasize the need for future research on test uptake and delivery of services in China's methadone clinics. Greater attention to young individuals and methadone clinic personnel are warranted. Increasing healthcare personnel at methadone clinics may increase test uptake. The use of multilevel modeling allowed examination of clinic level attributes of test uptake.

\section{Competing interests}

The authors declared that they have no competing interests.

\section{Authors' contributions}

YX contributed to paper writing and data analysis. WC contributed to data collecting and data analysis. JDT contributed to paper writing and analysis. CW contributed to paper writing. The corresponding author, $\mathrm{LL}$, contributed to funding application and supervision on project conducting. All authors read and approved the final manuscript.

\section{Acknowledgments}

This research was funded by National Natural Science Foundation of China (grant 30972552, grant 71173245), Guangdong Natural Science Foundation (grant 9151008901000023), the China Medical Board (grant 09-984), and National Institutes of Health (grant 1K01TW008200-01A1 and 1D43TW009532-01).

We sincerely appreciate Guangdong Health Bureau and Centre for Disease Control and Prevention of Guangdong Province for their effort on coordination with clinics. We are also thankful to all individuals and clinical staff for their participation.

\section{Author details}

${ }^{1}$ Faculty of Medical Statistics and Epidemiology, School of Public Health, Sun Yat-sen University, No. 74, Zhongshan Road II, Yuexiu District, Guangzhou 510080, P.R. China. ${ }^{2}$ Sun Yat-sen Center for Migrant Health Policy, Sun Yat-sen University, No. 74, Zhongshan Road II, Yuexiu District, Guangzhou 510080, P.R. China. ${ }^{3}$ UNC Project-China, Guangdong STD Control Center, Guangzhou 510095, P.R. China. ${ }^{4}$ Division of Gastroenterology, Rhode Island Hospital / Alpert Medical School of Brown University, 593 Eddy Street, APC 414, Providence, RI 02903, USA.

Received: 15 February 2013 Accepted: 27 September 2013 Published: 30 September 2013

\section{References}

1. Cohen MS, Chen YQ, McCauley M, Gamble T, Hosseinipour MC, Kumarasamy N, Hakim JG, Kumwenda J, Grinsztejn B, Pilotto JH, et al: Prevention of HIV-1 infection with early antiretroviral therapy. N Engl J Med 2011, 365:493-505.

2. Montaner JS, Lima VD, Barrios R, Yip B, Wood E, Kerr T, Shannon K, Harrigan PR, Hogg RS, Daly P, Kendall P: Association of highly active antiretroviral therapy coverage, population viral load, and yearly new HIV diagnoses in British Columbia, Canada: a population-based study. Lancet 2010, 376:532-539.
3. Asher AK, Hahn JA, Couture MC, Maher K, Page K: People who inject drugs, HIV risk, and HIV testing uptake in Sub-Saharan Africa. J Assoc Nurses AIDS Care 2012. doi:10.1016/j.jana.2012.09.003.

4. Saw YM, Yasuoka J, Saw TN, Poudel KC, Tun S, Jimba M: What are the factors associated with HIV testing among male injecting and non-injecting drug users in Lashio, Myanmar: a cross-sectional study. BMJ Open 2013, 3. doi:10.1136/bmjopen-2013-002747.

5. UNAIDS: UNAIDS Statement on Strengthening HIV Testing. Beijing: UNAIDS: 2012.

6. Zhang L, Gray RT, Wilson DP: Modelling the epidemiological impact of scaling up HIV testing and antiretroviral treatment in China. Sex Health 2012, 9:261-271.

7. Ma L-P, Zeng T-T, Bao Y-P, Hu H: Comparison and analysis on performance of voluntary counseling and testing (VCT) in China from 2005 to 2007. Chin J Dis Control Prev 2011, 15:199-202.

8. Wu Z, Sun X, Sullivan S, Detels R: HIV testing in China. Science 2006, 312:1475-1476.

9. Bao YP, Liu ZM: Systematic review of HIV and HCV infection among drug users in China. Internation J STD \& AIDS 2009, 20:399-405.

10. Garten RJ, Zhang J, Lai S, Liu W, Chen J, Yu XF: Coinfection with HIV and hepatitis $C$ virus among injection drug users in southern China. Clin Infect Dis 2005, 41(Suppl 1):S18-S24.

11. Klein M, Rollet K, Saeed S, Cox J, Potter M, Cohen J, Conway B, Cooper C, Cote P, Gill J, et al: HIV and hepatitis $C$ virus coinfection in Canada: challenges and opportunities for reducing preventable morbidity and mortality. HIV Med 2012. doi:10.1111/j.1468-1293.2012.01028.x.

12. China National Narcotics Control Committee: Annual Report on Drug Control in China, 2011. Beijing: China National Narcotics Control Committee; 2011.

13. Ministry of Health of China, Ministry of Public Security of China, State Food and Drug Administration: Work Plan of Community Maintenance Treatment for Opioid Addicts. Beijing: Ministry of Health of China; 2006.

14. State Council of P.R. of China: China's Action Plan for Reducing and Preventing the Spread of HIV/AIDS(2011-2015). Beijing: State Council of P.R. of China; 2012.

15. National Working Group on Community-based Methadone Maintenance Treatment for Opium Dependents: Report on Implementation of Communitybased Methadone Maintenance Treatment. Guiyang: National Conference on Experience in Community-based Methadone Maintenance Treatment for Opium Dependents; 2010.

16. Statistics Bureau of GuangDong Province: Nationwide Census in 2010. http:// www.gdstats.gov.cn/tjgb/t20110511_83329.htm.

17. Mao Y, Wu Z, Poundstone K, Wang C, Qin Q, Ma Y, Ma W: Development of a unified web-based national HIV/AIDS information system in China. Int J Epidemiol 2010, 39(Suppl 2):ii79-ii89.

18. Tucker JD, Yang LG, Yang B, Zheng HP, Chang H, Wang C, Shen SY, Zhu ZJ, Yin YP, Subramanian SV, et al: A twin response to twin epidemics: integrated HIV/syphilis testing at STI clinics in South China. J Acquir Immune Defic Syndr 2011, 57:e106-e111.

19. Goldstein H: Multilevel Statistical Models. 3rd edition. London: Hodder Arnold; 2003.

20. World Health Organization Regional Offices for South-East Asia and the Western Pacific: Scaling Up HIV Testing and Counselling in Asia and the Pacific. Manila, Philippines: World Health Organization; 2007.

21. National Centre for AIDS/STD Control and Prevention, China Centers for Disease Control and Prevention: Evaluation Workbook on Community-based Methadone Maintenance Treatment for Opium Dependents (trial). Beijing: China Centers for Disease Control and Prevention; 2007.

22. Wang C, Yang Y-H, Li H-L, Huang F-J, Dong C-L, Zhang Y, Xie B, He Z: Effectiveness of voluntary AIDS counseling and testing service in STI clinics. Soft Sci Health 2012, 26:406-408.

23. Day CA, White B, Thein HH, Doab A, Dore GJ, Bates A, Holden J, Maher L: Experience of hepatitis $C$ testing among injecting drug users in Sydney, Australia. AIDS Care 2008, 20:116-123.

24. Du J, Lombardi C, Evans E, Jiang H, Zhao M, Meng YY: A mixed methods approach to identifying factors related to voluntary HIV testing among injection drug users in Shanghai, China. Int J Infect Dis 2012. doi:10.1016/j. ijid.2012.02.013.

25. Hadland SE, Milloy MJ, Kerr T, Zhang R, Guillemi S, Hogg RS, Montaner JS, Wood E: Young age predicts poor antiretroviral adherence and viral load suppression among injection drug users. AIDS Patient Care STDS 2012, 26:274-280 
26. Hayashi K, Montaner J, Kaplan K, Suwannawong P, Wood E, Qi J, Kerr T: Low uptake of hepatitis $C$ testing and high prevalence of risk behavior among HIV-positive injection drug users in Bangkok, Thailand. J Acquir Immune Defic Syndr 2011, 56:e133-e135.

27. Pugatch D, Anderson BJ, O'Connell JV, Elson LC, Stein MD: HIV and HCV testing for young drug users in Rhode Island. J Adolesc Health 2006, 38:302-304.

28. United Nations Office on Drugs and Crime: HIV prevention among young injecting drug users. New York: United Nations Office on Drugs and Crime; 2004.

29. Worthington C, Jackson R, Mill J, Prentice T, Myers T, Sommerfeldt S: HIV testing experiences of aboriginal youth in Canada: service implications. AIDS Care 2010, 22:1269-1276.

30. Denison JA, McCauley AP, Dunnett-Dagg WA, Lungu N, Sweat MD: HIV testing among adolescents in Ndola, Zambia: how individual, relational and environmental factors relate to demand. AIDS Educ Prev 2009, 21:314-324.

31. Kabiru CW, Beguy D, Crichton J, Zulu EM: HIV/AIDS among youth in urban informal (slum) settlements in Kenya: what are the correlates of and motivations for HIV testing? BMC Public Health 2011, 11:685.

32. Addis Z, Yalew A, Shiferaw Y, Alemu A, Birhan W, Mathewose B, Tachebele $B$ : Knowledge, attitude and practice towards voluntary counseling and testing among university students in North West Ethiopia: a cross sectional study. BMC Public Health 2013, 13:714.

33. Kacanek D, Eldridge GD, Nealey-Moore J, MacGowan RJ, Binson D, Flanigan TP, Fitzgerald CC, Sosman JM: Young incarcerated men's perceptions of and experiences with HIV testing. Am J Public Health 2007, 97:1209-1215.

34. Bao YP, Du C, Lu HY, Lian Z, Qiu Y, Mu Y, Yan SY, Liu ZM: The investigation of HIV and $\mathrm{HCV}$ infection and risk factors among opiate drug users in Beijing, China. Am J Drug Alcohol Abuse 2012, 38:140-145.

35. Yin W, Hao Y, Sun X, Gong X, Li F, Li J, Rou K, Sullivan SG, Wang C, Cao X, et al: Scaling up the national methadone maintenance treatment program in China: achievements and challenges. Int J Epidemiol 2010, 39(Suppl 2):ii29-ii37.

36. Han L, Ling L, Xia Y-H, Chen W, Chen A, Chen J, He Q: Status quo and policy recommentations of methadone maintenance treatment clinics in Guangdong Province. Chin J Health Policy 2010, 3:34-38.

37. Shoptaw S, Stein JA, Rawson RA: Burnout in substance abuse counselors. Impact of environment, attitudes, and clients with HIV. J Subst Abuse Treat 2000, 19:117-126

38. Lin C, Wu Z, Rou K, Pang L, Cao X, Shoptaw S, Detels R: Challenges in providing services in methadone maintenance therapy clinics in China: service providers' perceptions. Int J Drug Policy 2010, 21:173-178.

doi:10.1186/1471-2458-13-899

Cite this article as: Xia et al.: HIV and hepatitis $C$ virus test uptake at methadone clinics in Southern China: opportunities for expanding detection of bloodborne infections. BMC Public Health 2013 13:899.

\section{Submit your next manuscript to BioMed Central and take full advantage of:}

- Convenient online submission

- Thorough peer review

- No space constraints or color figure charges

- Immediate publication on acceptance

- Inclusion in PubMed, CAS, Scopus and Google Scholar

- Research which is freely available for redistribution 